\title{
O QUADRO DAS DISPENSAS DA EDUCAÇÃO FÍSICA ESCOLAR NA REDE ESTADUAL PAULISTA
}

Fernanda Moreto Impolcetto, Universidade Estadual Paulista - UNESP, Rio Claro, São Paulo - Brasil

Osmar Moreira de Souza Junior, Universidade Federal de São Carlos - UFSCAR, São Carlos, São Paulo - Brasil

Heitor de Andrade Rodrigues, Universidade Federal de Goiás - UFO, Goiás - Brasil

André Luis Ruggiero Barroso, Faculdade de Jaguariúna - FAJ, Jaguariúna, São Paulo Brasil

André Minuzzo de Barros, Universidade Nove de Julho, São Paulo - Brasil

Anoel Fernandes, Pontifícia Universidade Católica de São Paulo - PUCSP, São Paulo Brasil

Laércio Claro Franco, Faculdade Metrocamp, Campinas, São Paulo - Brasil

Odainton Pollon Lopes, Prefeitura Municipal de Osasco, Osasco, São Paulo - Brasil

Augusto Barbosa Guimarães, Serviço Social do Comércio - SESC, Ribeirão Preto, São

Paulo - Brasil

João Ramos de Sousa Junior, Prefeitura Municipal de Jardinópolis, São Paulo - Brasil

Matheus de Falco Soares de Oliveira, Secretaria Municipal de Ribeirão Preto, Ribeirão Preto - Brasil

Suraya Cristina Darido, Universidade Estadual Paulista - UNESP, Rio Claro, São Paulo Brasil

\section{RESUMO}

Considerando que a legislação em vigor incorpora itens que permitem dispensas das aulas de Educação Física, o presente estudo teve por objetivo verificar a incidência das mesmas no Ensino Médio, em escolas da rede estadual paulista que oferecem aulas no período diurno e noturno. A metodologia do estudo baseou-se na realização de entrevistas semiestruturadas com professores, diretores e coordenadores de sete escolas. Os resultados apontam que o maior índice de dispensa ocorre nos cursos noturnos, nos quais as aulas são oferecidas fora do horário regular, o que permite concluir que este é um dos principais fatores responsáveis pelas dispensas.

Palavras-Chave: Educação Física escolar; Dispensas; Atestados; Componente curricular; Legislação.

\section{AN OVERVIEW OF PHYSICAL EDUCATION WAIVERS IN SÃO PAULO STATE SCHOOLS}

\begin{abstract}
Considering legislation allows students to be excused from P.E. classes, the purpose of this research is to verify the incidence of waivers in São Paulo state high schools. The research method adopted was semi structured interviews with teachers, directors and coordinators of seven schools. The results show that the majority of waivers are requested by evening
\end{abstract}


courses students, to whom P.E. is offered apart of the regular course schedule. Therefore, we can conclude this is the main reason why participation is waived.

Key-Words: Physical Education classes; Waivers; Waiver forms; Curriculum; Legislation.

\section{GRÁFICO DE FALTAS EN LAS CLASES DE EDUCACIÓN FISICA DE LOS COLEGIOS PÚBLICOS PAULISTAS}

\section{RESUMEN}

Considerando que la legislación actual incorpora elementos que permiten excepciones en las clases de Educación Física, el presente estudio tuvo como objetivo verificar la incidencia de las mismas en la secundaria, en escuelas públicas paulistas, que ofrecen clases durante el día y el período nocturno. La metodologia del estudio se basó en la realización de entrevistas semi-estructuradas con los profesores, directores y coordinadores de siete escuelas. Los resultados indican que el mayor índice de faltas se produce en clases nocturnas, donde se ofrecen clases fuera del horário habitual, lo que sugiere que este es uno de los principales factores responsables por las ausências.

Palabras-Claves: Educación Física escolar; Excepciones; Certificados médicos; Componente acadêmico; Legislación. 


\section{INTRODUÇÃO}

Ao longo da trajetória da Educação Física na escola, diversas foram as possibilidades de dispositivos legais que permitiram aos alunos solicitarem dispensas das aulas. Mais especificamente, essas leis foram aprovadas nas décadas de 1960 e 1970 e admitiam que alunos com problemas de saúde, que servissem o exército, que tivessem filhos (prole), trabalhassem e tivessem mais de trinta anos, fossem liberados das aulas de Educação Física escolar.

Essas práticas de dispensa eram ou podiam ser respaldadas pelo fato da Educação Física ser considerada na lei como atividade e não disciplina como as demais áreas que compõem o currículo escolar. Para alguns autores essa consideração compreendia a Educação Física como prática pela prática, sem necessidade de uma estruturação dos seus conteúdos. ${ }^{1-2}$

Em 1996 foi aprovada a nova Lei de Diretrizes e Bases (9394/96) que mudava consideravelmente o cenário para a Educação Física, propondo considerá-la como componente curricular, assim como todas as demais disciplinas do currículo. Essa mudança apontou para avanços significativos, pelo menos perante a legislação, pois permitiu almejar uma Educação Física diferente da praticada até então.

Após esse período, esperava-se que as dispensas das aulas de Educação Física não poderiam mais ser aceitas nas escolas, uma vez que a lei das dispensas referia-se a algo considerado "atividade" e não "componente curricular". Entretanto, numa situação de análise da realidade das aulas de Educação Física na escola, constatava-se que os professores continuavam a aceitar as diferentes dispensas, ou seja, não houve um debate suficiente e/ou apoio aos professores no sentido de recusarem as solicitações de dispensas.

Surpreendentemente, em 2003 foi aprovada uma lei que alterou a redação do artigo 26, parágrafo $3^{\circ}$, garantindo a dispensa das aulas de Educação Física aos alunos que tem filhos, mais de trinta anos, que estejam cumprindo serviço militar obrigatório, que trabalhem seis horas ou mais por dia e por motivos de saúde.

Ao contrário da discussão realizada até o momento, na qual se defende a inclusão de todos os alunos, a lei aprovada tem uma visão bastante excludente do papel da Educação Física na 
escola. Retomam-se os pressupostos de corpo exclusivamente biológico, homogêneo, cansado do trabalho, velho ou doente, que não tem condições para realizar as aulas da escola.

Qual a razão da lei das dispensas retornar no ano de 2003? Como se deve interpretar essas dispensas? As dispensas são das aulas ou das práticas da Educação Física na escola? Quais as conseqüências das dispensas para o imaginário social dos atores escolares e para a comunidade em geral? Como os professores de Educação Física se sentem perante essas dispensas? Como lidam com elas no cotidiano escolar? Quantos alunos têm se utilizado delas? Em quais situações?

Enfim, é possível levantar uma série de questionamentos para o universo escolar. Dentre essas indagações, o objetivo do presente estudo foi verificar a incidência das dispensas nas aulas de Educação Física em escolas de Ensino Médio da rede estadual de São Paulo que possuem aulas tanto no período diurno quanto noturno.

Buscamos centrar o foco na análise da realidade da Educação Física na escola, para verificar as diferenças entre o número de alunos dispensados quando a Educação Física é oferecida no mesmo período das demais disciplinas e quando é oferecida em outro período, como acontece nos cursos noturnos.

Essas informações podem facilitar a realização de um diagnóstico inicial sobre a situação concreta das dispensas nas aulas de Educação Física e a partir daí apontar algumas perspectivas que podem auxiliar o professor a abordar essa questão, tanto no Projeto Político Pedagógico da escola como perante a comunidade escolar e também no encaminhamento de políticas educacionais que considerem a inclusão.

\section{REVISÃO BIBLIOGRÁFICA}

Verificamos que existem poucos trabalhos que tratam da dispensa nas aulas de Educação Física. Entre os consultados, existem algumas dúvidas comuns como: qual o real significado da palavra dispensa descrito na lei? Quais condições dão o direito ao aluno de ter essa dispensa? Quais os motivos que levam os alunos das séries mais avançadas a terem o maior 
número de dispensa que os de séries iniciais? Qual o motivo de, em algumas escolas, as aulas de Educação Física serem realizadas em horário contrário ao das demais disciplinas?

De acordo com Gambine ${ }^{3}$ existem muitas desvantagens quando as aulas ocorrem no período inverso, sua pesquisa indica que 93\% dos alunos dispensados participariam das aulas de Educação Física, caso elas fossem realizadas no horário de aula. Dos 30 professores entrevistados, 22 afirmaram preferir as aulas no mesmo período, e 20 relataram a diminuição do número de dispensas e das faltas nas aulas, quando realizadas junto com as demais disciplinas.

Cauduro ${ }^{4}$ constatou que a obrigatoriedade de comparecimento nas aulas de Educação Física em período oposto ao das aulas, dificulta o acesso a atividades extracurriculares. Há também os problemas de quem depende de ônibus para voltar à escola.

Em pesquisa realizada por Darido ${ }^{5}$, relacionada ao afastamento dos alunos da prática de Educação Física Escolar, foi verificado que apesar de 50\% dos alunos do $1^{\circ}$ ano do Ensino Médio considerarem a Educação Física como sua matéria preferida, aproximadamente 20\% são dispensados das aulas na escola. De acordo com a autora é possível que as solicitações de dispensa ocorram principalmente nas escolas que oferecem a disciplina fora do período.

Souza Junior e Darido ${ }^{6}$ apresentam o resultado de um trabalho desenvolvido numa escola privada de uma cidade do interior do estado de São Paulo, com o objetivo de diminuir o número de dispensas no Ensino Médio. Num período crítico, o número total de alunos do Ensino Médio dessa escola, dispensados das aulas de Educação Física chegou a 48,8\%, ou seja, praticamente metade dos alunos não participavam das aulas.

De acordo com Souza Junior e Darido, ${ }^{6}$ alguns fatores podem ser considerados determinantes para a cristalização dessa cultura das dispensas, como: aulas fora do período das outras disciplinas, critérios e controle para a triagem das dispensas muito frágeis, inexistência de notas bimestrais para os alunos dispensados e a propagação de uma cultura que era repassada entre os alunos de que as dispensas eram comuns. 
A adoção de um programa de avaliações pela disciplina de Educação Física, que foi transformado ao longo de cinco anos, no seu último formato incluía a entrega de um trabalho escrito, a apresentação desse trabalho em forma de seminário e uma prova, baseados num artigo científico da área da Educação Física, conseguiu reduzir as dispensas de $33,5 \%$ para apenas $2,7 \%$. Os autores concluem que apesar da legislação, é possível a construção de mecanismos que minimizem as dispensas nas aulas de Educação Física. ${ }^{6}$

A primeira Lei de Diretrizes e Bases da Educação Nacional foi promulgada no ano de 1961 e de acordo com o artigo 22 da Lei no 4.024/61, a prática da Educação Física era obrigatória nos cursos Primário (Educação pré-primaria e Ensino Primário) e Médio (Ginásio e Colégio) aos alunos com idade até 18 anos.

De acordo com Castellani Filho, ${ }^{7}$ os motivos que justificavam sua presença na educação, estavam relacionados ao processo de industrialização da economia brasileira e na necessidade de capacitar fisicamente os trabalhadores, auxiliando no processo de formação de um corpo produtivo, forte e saudável, que ao mesmo tempo fosse dócil a ponto de ser submetido ao trabalho fabril, sem questioná-lo.

$\mathrm{O}$ autor indica ainda que, sua prática estabelecida até a idade de 18 anos, justifica-se pela compreensão de ser nesta idade o final do processo de escolarização e subseqüentemente o ingresso no mercado de trabalho, ao qual caberia a partir de então, os cuidados com a manutenção da capacitação física dos trabalhadores.

Uma reforma educacional ocorreu dez anos depois, sendo que a denominação de Educação de Grau Primário e Médio passou para Ensino de $1^{\circ}$ e $2^{\circ}$ Grau. Em relação à Educação Física o artigo $7^{\circ}$ da Lei $n^{\circ} 5.692$ de 11 de agosto de 1971, deixou de fazer referência ao limite de idade de obrigatoriedade da prática, tornando-se obrigatória em todos os níveis de ensino e facultativa ao aluno que estivesse em alguma das seguintes condições:

- Trabalhasse mais de 6 horas por dia e estudasse à noite;

- Tivesse mais de 30 anos de idade;

- Prestasse serviço militar;

- Fosse fisicamente incapacitado. 
No Ensino Superior a Educação Física já havia sido introduzida desde 1968, por ocasião da reforma universitária promovida pelo governo militar, que de acordo com Sousa e Vago ${ }^{8}$ tinha por intenção desmobilizar politicamente os estudantes, distraindo-os com a prática esportiva.

Sobre a LDB de 1971 (5692/71), Castellani Filho ${ }^{7}$ indica que o fato de tornar facultativa a prática da Educação Física para o aluno que trabalhava e estudava à noite, reforçava a lógica de que a responsabilidade pela capacitação física e sua manutenção, estava relegada ao mercado de trabalho e não mais à escola.

Facultá-la ao aluno com mais de 30 anos, expressava a compreensão de que com esta idade, ele já estaria na condição de provedor de família e em decorrência disso, vinculado ao mercado de trabalho, que como anteriormente destacado, seria responsável pela manutenção da capacidade física dos funcionários.

Em relação ao aluno que estivesse prestando serviço militar, as atividades físicas praticadas nas Forças Armadas já seriam suficientes para sua formação, não havendo, portanto, necessidade de prática nas aulas de Educação Física escolar.

Por fim, facultá-la ao aluno que estivesse fisicamente incapacitado expressa a concepção de que as atividades realizadas nas aulas de Educação Física não precisavam ser pensadas, refletidas, conceituadas, enfim, eram apenas voltadas para a prática.

Ainda no ano de 1971, o Decreto 69.450 atribuiu uma nova regulamentação específica à Educação Física, que passou a ser concebida como: "atividade que por seus meios, processos e técnicas, desperta, desenvolve e aprimora forças físicas, morais, cívicas, psíquicas e sociais do educando, constituindo um dos fatores básicos para a conquista das finalidades da educação nacional". 1:104

De acordo com Castellani Filho (2003) o termo atividade empregado no texto legal, tem sua definição expressa formalmente no Parecer $n^{\circ} 853$ de 12 de novembro de 1971, do Conselho Federal de Educação (CFE) e na Resolução no 8 de 01/12/1971 daquele mesmo Conselho, adquirindo um significado de um fazer prático, não significativo de uma reflexão teórica. 
Segundo a própria redação do Parecer: “[...] nas atividades, as aprendizagens desenvolverse-ão antes sobre experiências colhidas em situações concretas do que pela apresentação sistemática dos conhecimentos [...]". 2:108

O autor afirma ainda que a concepção de Educação Física enquanto atividade que aparece incorporada nos currículos, explica e justifica a sua presença na instituição escolar, na medida em que esta ação não necessitava de uma reflexão teórica caracterizada pelo "fazer pelo fazer", não se configura em um campo de conhecimento dotado de um saber próprio, mas sim enquanto uma mera experiência limitada em si mesma, destituída do exercício da sistematização e compreensão do conhecimento, existente apenas empiricamente. ${ }^{2}$

Em 1977, por meio da Lei $\mathrm{n}^{\circ}$ 6.503/77 mais duas alíneas foram incorporadas à lei, e facultavam a prática das aulas de Educação Física ao aluno de pós-graduação e à mulher com prole. No primeiro caso, verifica-se que pelo fato dos estudos da pós-graduação estarem ligados ao trabalho intelectual, não haveria necessidade de capacitação física para o mercado de trabalho, por isso não era necessário freqüentar estas aulas. No segundo, fica claro como a sociedade encarava o papel da mulher, a qual cabia a criação dos filhos, já que o marido era o responsável pelo sustento da família. ${ }^{7}$

Estas reflexões nos ajudam a compreender o papel que a Educação Física assumiu historicamente no cenário escolar e os desdobramentos desta concepção de Educação Física, para a construção de um estereótipo da disciplina, caracterizado pela sua singularidade no contexto escolar. Tais aspectos levam alunos, professores e a comunidade escolar, bem como a sociedade de uma maneira geral, a não reconhecer o professor de Educação Física, tampouco suas aulas como parte do projeto pedagógico da escola, mas sim como atividade extra-curricular voltada para o treinamento, a saúde e para o lazer.

O parágrafo $3^{\circ}$ do artigo 26 da LDB no 9394/96 determina que: “A educação física, integrada à proposta pedagógica da escola, é componente curricular da Educação Básica, ajustando-se às faixas etárias e às condições da população escolar, sendo facultativa nos cursos noturnos".9 A Educação Física torna-se obrigatória no agora Ensino Básico; facultativa nos cursos noturnos, ficando a cargo da escola oferecer ou não e dos alunos freqüentar ou não (por ser facultativo não faz parte das 800 horas anuais obrigatórias de 
ensino); deixa de ser componente obrigatório no Ensino Superior, ficando facultativo às Faculdades oferecerem a disciplina.

De acordo com Silva e Venâncio ${ }^{10}$ essa alteração não trouxe as mudanças esperadas, tendo em vista que a redação genérica do artigo não garantia a presença das aulas de Educação Física em todas as etapas da Educação Básica e, muito menos, que os profissionais que ministrassem essas aulas contassem com formação específica.

Apesar de indicar a inclusão da Educação Física como componente da Educação Básica, a lei deixa de expressar sua obrigatoriedade, o que permitiria leituras e ações equivocadas quanto a sua permanência nas várias etapas da Educação Básica.

No intuito de garantir a presença e enfatizar a necessidade da Educação Física na Educação Básica, em 2001 foi alterado o texto do artigo $26 \mathrm{em}$ seu parágrafo $3^{\circ}$ incluindo a palavra "obrigatório" a frente da expressão "componente curricular", o que garantiu a exigência legal da Educação Física na Educação Infantil, no Ensino Fundamental e Ensino Médio. Contudo, Silva e Venâncio ${ }^{10}$ afirmam que a simples inclusão do termo "obrigatório" não proporciona mudanças substanciais à legislação, pelo fato de, entre outros fatores não garantir a disciplina em todas as séries da Educação Básica.

A lei não explicita conceitos, objetivos, nem conteúdos para a disciplina, mas apresenta dois condicionantes: integrar-se à proposta pedagógica da escola, ajustar-se às faixas etárias e às condições da população escolar. A carga horária anual, o número de aulas, a composição das turmas, a duração da aula e o espaço de ensino fica sob decisão de cada escola, secretarias municipais e estaduais.

Outra lacuna da LDB 1996, referente ao seu $\S 3^{\circ}$ do artigo 26, foi a permanência do termo "facultativo aos cursos noturnos", nesse sentido uma grande parcela da população escolar não tinha acesso aos conhecimentos veiculados por esse componente curricular, já que a escola não oferecia as aulas ou quando oferecia os alunos poderiam optar em não participar.

Tentando reverter essa situação, o texto do $\S 3^{\circ}$ do artigo 26 foi novamente alterado. Por meio da Lei 10.793 de 01/12/2003 as aulas passam a ser facultativas não mais a todas as 
pessoas que estudassem no período noturno, mas àqueles que se enquadrassem nas seguintes condições: mulheres com prole, trabalhadores, militares e pessoas com mais de 30 anos. Portanto, tal facultatividade estendeu-se aos alunos que se incluem nesse grupo, independentemente do período de estudo. ${ }^{10}$

Em nosso entendimento um retrocesso, visto que os critérios adotados para garantia da facultatividade estão nitidamente permeados de uma visão da Educação Física como atividade eminentemente prática, ou seja, que provoca o cansaço físico do aluno, concepções reducionistas de compreender a Educação Física na escola e que priva uma parcela da população escolar de conhecer e vivenciar as manifestações da cultura corporal de movimento.

Silva e Venâncio ${ }^{10}$ alertam ainda para o fato de que a lei 10.793 permite interpretações equivocadas, interpretações estas que tem sido usadas como mecanismo para burlar a própria lei, o qual consiste na aceitação por parte das escolas de atestados médicos para a dispensa das aulas de Educação Física.

Apenas os alunos amparados pelo Decreto Lei 1.044, de 21 de outubro de 1969, devem ficar afastados das aulas de Educação Física, assim como dos demais componentes curriculares, por incapacidade física que o impossibilite de freqüentar as aulas. Tal incapacidade pode ser decorrente de afecções congênitas ou adquiridas, infecções, traumatismos ou outras condições.

Os outros fatores de dispensa previstos na lei não justificam o afastamento dos alunos das aulas, pois, mesmo que não possam participar das atividades práticas, devem comparecer às aulas, considerando que a Educação Física é uma componente curricular como os demais e não se restringe apenas a atividades desta natureza.

\section{METODOLOGIA}

Tendo o presente estudo a intenção de compreender e interpretar um determinado fenômeno social optou-se pela realização de uma pesquisa descritiva com abordagem qualitativa. 
Para o desenvolvimento desta pesquisa, primeiramente analisou-se o texto vigente da LDB 9394/96, sobre a normatização do componente curricular Educação Física, com ênfase para os aspectos das dispensas, assim como os textos anteriores, além de outros artigos que tratam da questão das dispensas nas aulas de Educação Física.

Posteriormente, durante o primeiro semestre de 2011, por questão de disponibilidade, alguns dos autores desse estudo, realizaram entrevistas semi-estruturadas com professores de Educação Física, diretores e coordenadores de escolas de Ensino Médio da rede de ensino do Estado de São Paulo, de suas respectivas cidades.

A escolha das escolas atendeu ao requisito de oferecerem aulas para o Ensino Médio tanto no período diurno, quanto noturno e contarem com funcionários dispostos a responder aos questionários que seguem. Primeiramente sobre as aulas do período diurno:

1. Quantos professores de Educação Física têm na escola?

2. As aulas de Educação Física são no período das outras disciplinas ou no período contrário?

3. Número de alunos, dispensas e motivos.

4. O aluno ou aluna é dispensado da aula ou da prática?

5. Como fica o registro (freqüência, avaliações etc.) desses alunos dispensados?

Sobre as aulas de Educação Física do noturno:

1. Os alunos do período noturno têm aulas de Educação Física?

2. Quantos professores de Educação Física têm na escola? A quem as aulas são atribuídas?

3. As aulas de Educação Física são no período das outras disciplinas ou no período contrário?

4. Número de alunos, dispensas e motivos.

5. O aluno ou aluna é dispensado da aula ou da prática?

6. Como fica o registro (freqüência, avaliações etc.) desses alunos dispensados? 


\section{RESULTADOS E DISCUSSÃO}

A seguir serão apresentados os resultados dos dados coletados em sete escolas estaduais de

Ensino Médio que oferecem aulas nos períodos diurno e noturno.

O Quadro 1 apresenta os dados referentes às perguntas 1, 2 e 4 do questionário sobre as aulas de Educação Física dos alunos que estudam no período diurno.

Quadro 1 - Número de professores de Educação Física, período das aulas e forma da dispensa

\begin{tabular}{lccc}
\hline & $\begin{array}{c}\text { Número de } \\
\text { professores de } \\
\text { Educação Física }\end{array}$ & $\begin{array}{c}\text { A aula acontece no mesmo } \\
\text { período das outras } \\
\text { disciplinas? }\end{array}$ & $\begin{array}{c}\text { O aluno é dispensado da aula ou } \\
\text { da prática? }\end{array}$ \\
\hline Escola 1 & 4 & Sim & Da prática \\
Escola 2 & 4 & Sim & Da prática \\
Escola 3 & 1 & Sim & Da prática \\
Escola 4 & 3 & Sim & Da aula \\
Escola 5 & 2 & Sim & Da prática \\
Escola 6 & 2 & Sim & Da aula \\
Escola 7 & 1 & Sim & Da prática \\
\hline
\end{tabular}

Um dado importante que pode ser verificado no quadro é o fato das aulas de Educação Física nas sete escolas acontecerem no mesmo período que o das demais disciplinas, o que certamente inibe o pedido das dispensas por parte dos alunos. Além disso, em apenas duas escolas o aluno é totalmente dispensado da aula, enquanto nas demais, ele é dispensado apenas da prática, ou seja, tem que comparecer e assistir às aulas. Tais resultados apontam para diferentes leituras sobre o que significa dispensa.

O Quadro 2 apresenta o número de alunos em cada série do Ensino Médio do período diurno, o número de alunos dispensados e os motivos.

Quadro 2 - Total de alunos, alunos dispensados e motivos.

\begin{tabular}{cllllllllll}
\hline & \multicolumn{4}{c}{$\mathbf{1}^{\mathbf{0}}$ ano } & \multicolumn{4}{c}{$\mathbf{2}^{\mathbf{o}}$ ano } & \multicolumn{3}{c}{$\mathbf{3}^{\mathbf{0}}$ ano } & \% Disp \\
Escola & $\mathbf{n}^{\mathbf{o}}$ al & Disp & Motivos & $\mathbf{n}^{\mathbf{0}}$ al & Disp & Motivos & $\mathbf{N}^{\mathbf{o}}$ al & Disp & Motivos & \\
\hline $\mathbf{1}$ & 168 & 0 & --------- & 142 & 1 & saúde & 120 & 0 & ------- & $0,23 \%$ \\
$\mathbf{2}$ & 95 & 1 & saúde & 94 & 2 & saúde & 81 & 6 & saúde & $3,33 \%$ \\
$\mathbf{3}$ & 135 & 0 & ---------- & 90 & 0 & --------- & 43 & 0 & ------- & $0,00 \%$ \\
$\mathbf{4}$ & 110 & 1 & gestante & 90 & 1 & gestante & 90 & 1 & saúde & $1,03 \%$ \\
$\mathbf{5}$ & 378 & 10 & saúde & 304 & 7 & saúde & 245 & 5 & saúde & $2,37 \%$ \\
$\mathbf{6}$ & 43 & 2 & gestante & 38 & 1 & gestante & 0 & 0 & ------- & $3,70 \%$ \\
$\mathbf{7}$ & 204 & 2 & saúde & 101 & 1 & saúde & 74 & 0 & ------ & $0,78 \%$ \\
\hline
\end{tabular}


Os resultados indicam que de um total de 2.645 alunos, 41 ou $0,64 \%$ dos alunos do Ensino Médio que estudam no período diurno e com as aulas de Educação Física no mesmo período dos demais componentes curriculares, são dispensados das aulas de Educação Física. Para a maior parte das dispensas, 36 ou $87,80 \%$, foi indicado motivo de saúde e para 5 delas ou $12,20 \%$, licença gestante.

Pesquisa realizada por Darido ${ }^{5}$ aponta que o índice de dispensas dos alunos do $1^{\mathrm{o}}$ ano do Ensino Médio foi de aproximadamente 20\%. A autora explica que esse número pode ser decorrente do fato de que as solicitações de dispensa ocorram principalmente nas escolas que oferecem a disciplina fora do horário das demais disciplinas. Nos dados levantados pela presente pesquisa, o fato das aulas de Educação Física acontecer no mesmo período das outras disciplinas certamente tem influência para que o número de dispensas seja reduzido.

Em relação ao modo como as dispensas são registradas, nas escolas em que os alunos são dispensados apenas da prática, a frequiência é computada pelos professores normalmente e os alunos são avaliados por meio de provas ou trabalhos.

Apenas em uma das escolas, a professora afirmou que registra média 6 para todos os alunos dispensados, sem cobrar trabalhos ou qualquer tipo de atividade para avaliação, diferentemente do que acontece nas demais escolas e do que apontam Souza Junior e Darido, ${ }^{6}$ que adotaram uma programa de avaliações para a disciplina com o intuito de diminuir o número de dispensas do Ensino Médio.

Já nas duas escolas em que os alunos são dispensados de participar das aulas, fazem trabalhos para compensação tanto de faltas quanto para nota.

O Quadro 3 apresenta os resultados dos dados coletados sobre os cursos do período noturno. 
Quadro 3 - Indica se as escolas oferecem aulas de Educação Física no período noturno, se elas são atribuídas a professores da área, quando elas ocorrem, o número de alunos que frequentam as escolas, o número de dispensas e o motivo, além da maneira como são registradas

\begin{tabular}{|c|c|c|c|c|c|c|}
\hline & $\begin{array}{c}\text { Constam } \\
\text { aulas de EF } \\
\text { na grade } \\
\text { curricular? }\end{array}$ & $\begin{array}{l}\text { A quem são } \\
\text { atribuídas? }\end{array}$ & $\begin{array}{l}\text { Período das } \\
\text { aulas }\end{array}$ & $\begin{array}{c}\mathbf{N}^{\mathbf{0}} \\
\text { alunos }\end{array}$ & $\mathbf{N}^{0}$ dispensas & Registro \\
\hline Escola 1 & Não & ----------- & ----------- & ----- & ----------- & ------------ \\
\hline Escola 2 & Sim & 1 prof. & Sábados & 84 & ------------- & $\begin{array}{l}\text { Presença para } \\
\text { todos }\end{array}$ \\
\hline Escola 3 & Não & ------------ & -------------- & 252 & --------------- & ---------------- \\
\hline Escola 4 & Sim & 3 profs. & Sábados & 249 & 249 trabalho & $\begin{array}{c}\text { Presença para } \\
\text { todos }\end{array}$ \\
\hline Escola 5 & Sim & -------------- & -------------- & 1066 & 1066 trabalho & --------------- \\
\hline Escola 6 & Sim & 2 profs & Sábados & 74 & 74 trabalho & $\begin{array}{l}\text { Presença para } \\
\text { todos }\end{array}$ \\
\hline Escola 7 & Não & ------------- & ------------ & 196 & 196 trabalho & -------------- \\
\hline
\end{tabular}

Em relação às aulas do período noturno, na escola 1 as aulas não são oferecidas aos alunos, portanto, não são atribuídas a nenhum professor e todos ficam dispensados por motivo de trabalho.

Na escola 3 também não são oferecidas aulas de Educação Física aos alunos do Ensino Médio do período noturno, sendo que no total a escola conta com 252 alunos nesse período.

$\mathrm{Na}$ escola 7, acontece a mesma coisa, no entanto a coordenadora explicou que se algum aluno deixar de entregar o atestado para dispensa, deve frequentar as aulas de Educação Física no período diurno com alguma turma correspondente ao seu ano de ensino. Sobre o registro dos alunos dispensados, a coordenadora indicou que a disciplina não entra na grade curricular dos alunos, por isso não há registros. Essa escola possui 196 alunos no período noturno e todos entregaram atestado de trabalho no início do ano.

Na escola 5, segundo a diretora, as aulas são oferecidas, mas os alunos são dispensados por atestado de trabalho. A escola conta com 1066 alunos nesse período e todos são dispensados.

Nas escolas 4 e 6 as aulas de Educação Física são oferecidas aos sábados, no entanto, todos os alunos são dispensados por motivo de trabalho, portanto, não freqüentam as aulas, mas a 
presença é registrada para todos. Na escola 4 as aulas são atribuídas a 3 professores e o total de alunos é de 249. Na escola 6 as aulas são atribuídas a 2 professores e total de alunos é de 74.

Em relação à escola 2, as aulas também são oferecidas aos sábados, ocorrendo junto com as atividades do projeto do governo estadual paulista Escola da Família e atribuídas a um professor efetivo, no entanto, como ele não tem o controle dos alunos que são dispensados, registra presença para todos e justifica que é necessário um número determinado de presenças para que essas aulas continuem sendo atribuídas e que ele precisa das aulas para complementar sua renda. A escola conta com 84 alunos no período noturno.

De modo geral, verifica-se que os maiores índices de dispensa incidem nas aulas de Educação Física dos cursos noturnos. Das escolas pesquisadas, em apenas uma as aulas ocorrem aos sábados, mas o professor indicou não ter o controle do número de alunos dispensados e também não informou quantos freqüentam as aulas efetivamente, enquanto nas demais, quando as aulas são oferecidas, todos os alunos são dispensados por motivo de trabalho.

O que se constata é que as aulas de Educação Física praticamente não existem nos cursos noturnos, ou seja, apesar de ser componente curricular, sua presença não está sendo garantida pela administração escolar, pois a mesma legislação que a torna obrigatória oferece possibilidades para que os alunos não participem dela.

Os alunos, ao serem dispensados da Educação Física, podem ser prejudicados em relação à formação escolar. Apontamos algumas possíveis conseqüências relacionadas ao déficit no processo educacional, pelo fato de não entrarem em contato com o conhecimento específico produzido pela área. De acordo com os $\mathrm{PCNs}^{11}$ o objetivo da Educação Física escolar é a inserção e a intervenção dos alunos na esfera da Cultura Corporal e a Educação Física apresenta um conhecimento ao longo da história, fazendo parte da construção cultural do Ser Humano.

A partir de 2009 o Enem adquire uma nova função, passando a compor o processo seletivo, principalmente das universidades federais. Neste mesmo ano a Educação Física passa a 
integrar a matriz de Linguagens Códigos e suas Tecnologias, uma das áreas de conhecimento do exame. Desde então, foram elaboradas e divulgadas quatro provas do ENEM até o ano de 2010, todas elas com questões relacionadas à área de Educação Física.

Souza Júnior e Darido ${ }^{12}$ identificaram em seu estudo, com base em análises das provas do ENEM de 2009 e 2010', a inclusão de 13 questões específicas da área de Educação Física. Com relação às temáticas representadas nas questões, os autores entendem que dois blocos de conteúdos se destacam, o primeiro deles englobaria as temáticas de exercício físico, corpo e saúde, envolvendo tanto a perspectiva biológica, quanto a das ciências humanas, este bloco esteve presente em todas as provas totalizando seis questões das 13 divulgadas. $\mathrm{O}$ segundo bloco refere-se à temática dança, também presente em todas as provas, somando quatro questões, cabendo destacar que este conteúdo também representa a área de Artes. As temáticas das três questões que não se enquadram nestes blocos são técnica esportiva, biomecânica do salto e jogos e brincadeiras.

Os alunos ao serem dispensados das aulas, poderiam ter dificuldade de entrar em contato com estes conhecimentos. Soares et al. ${ }^{13}$ sugerem que os conteúdos da Educação Física escolar estão divididos em jogo, esporte, ginástica, dança e luta. Os Parâmetros Curriculares Nacionais organizam os conteúdos em blocos, sendo apresentados como: conhecimento sobre o corpo; esportes, jogos, lutas e ginásticas; atividades rítmicas e expressivas. ${ }^{11}$

Os alunos têm também condições de entrarem em contato com determinados conteúdos, inclusive os da disciplina de Educação Física, em ambientes não formais de ensino, como é caso de clubes, secretarias municipais de esporte, academias, praças públicas, ou mesmo no convívio familiar, no entanto, aprender fora da escola exclui uma parcela significativa da população, justamente a que não tem acesso a esses espaços.

O que estamos questionando é a impossibilidade destes conteúdos serem apresentados e desenvolvidos a todos os alunos por meio de propostas metodológicas no interior da escola, pois, além de propiciar a vivência, também poderá levar o aluno à reflexão dos mesmos,

\footnotetext{
' Foram confeccionadas duas provas em 2009 em virtude de fraude na gráfica responsável pela impressão e também duas em 2010, desta vez em função de uma falha na impressão de parte dos cadernos de prova.

Conexões: revista da Faculdade de Educação Física da UNICAMP, Campinas, v. 12, n. 2, p. 50-69, abr./jun. 2014. 
buscando estabelecer uma visão crítica e questionadora sobre diversificadas práticas corporais.

Pelos dados levantados nessa pesquisa, de sete escolas, apenas uma oferece aulas de Educação Física para os alunos do Ensino Médio no período noturno, ou seja, a quantos alunos esses conteúdos deixam de ser transmitidos?

A não participação dos alunos nas aulas de Educação Física, rompe com o princípio da democracia do ensino e seu princípio de igualdade de oportunidade, uma vez que, somente alguns terão acesso aos conteúdos dessa disciplina, fato que vem acontecendo nos cursos noturnos de Ensino Médio, como verificado nessa pesquisa.

De acordo com os dados levantados por essa pesquisa, 100\% dos atestados de dispensa entregues pelos alunos do Ensino Médio noturno são de trabalho. Por que um estudante trabalhador não precisa ter acesso aos conhecimentos da Educação Física na escola?

Das sete escolas que participaram do estudo, em quatro delas a Educação Física faz parte do currículo, no entanto, as aulas são oferecidas aos sábados. Nas outras três escolas a Educação Física não é oferecida e também não é contemplada na grade curricular. O que justifica seu oferecimento fora da grade curricular em horários alternativos? É possível que essa disciplina seja omitida da grade curricular dos alunos dos cursos noturnos em que ela não é oferecida? Será que o conhecimento produzido e acumulado pela área não é significativo nem importante no processo de escolarização e formação dos alunos?

\section{CONSIDERAÇÕES FINAIS}

O objetivo do presente estudo foi verificar a incidência das dispensas nas aulas de Educação Física em escolas de Ensino Médio da rede estadual de São Paulo que possuem aulas tanto no período diurno quanto noturno.

Os dados coletados indicam que o índice de dispensas no período diurno é de apenas 0,64\% e os motivos são relacionados a problemas de saúde e licença gestante.

Já no período noturno, em quatro das escolas a Educação Física é oferecida aos sábados, fora do horário dos demais componentes curriculares, no entanto, em apenas uma delas os 
alunos frequentam as aulas, mas o professor que respondeu ao questionário não indicou o número de dispensados justificando não ter posse desses dados. Ele adota o procedimento de colocar presença para todos e as aulas acontecem concomitantemente ao projeto do governo estadual paulista Escola da Família, circunstância inclusive que impossibilitou a determinação de um índice para o número de dispensas no noturno, o que não deixa de ser um dado importante. Nas outras três escolas a Educação Física não é oferecida, portanto, não integra a grade curricular dos alunos que as frequentam.

De modo geral, os resultados permitem concluir que ainda existem diferentes interpretações sobre a dispensa dos alunos estarem relacionadas à prática ou à presença na aula de Educação Física. Nas aulas do período diurno as dispensas estão muito mais relacionadas à prática, apenas 14,63\% dos alunos são dispensados da aula. No período noturno, no entanto, $100 \%$ das dispensas são da aula, o que pode ser explicado, em parte, pelo fato que as aulas de Educação Física nesses cursos são oferecidas em períodos diferentes das outras disciplinas curriculares, como indica Darido. ${ }^{5}$

Os dados evidenciam a dificuldade dos gestores educacionais na interpretação da lei e no controle dos mecanismos de dispensa, que segundo Souza Junior e Darido ${ }^{6}$ podem ser utilizados para minimizar as dispensas das aulas de Educação Física do Ensino Médio. Além disso, nem a inclusão de questões específicas da disciplina no ENEM surtiu efeito no sentido de promover mudanças nesse quadro, na busca de garantir aos alunos o acesso aos conhecimentos da área.

Acreditamos, portanto, que é necessária uma revisão da concepção de Educação Física que vem servindo de referência para a elaboração das legislações que regem a Educação Básica em nosso país, tendo em vista que a perspectiva da disciplina enquanto área de conhecimento responsável por um saber que compreende as dimensões conceitual, procedimental e atitudinal, já se configura em uma realidade nas discussões acadêmicas e também em algumas práticas escolares. Contudo, é notório que estas discussões ainda não penetraram de forma significativa nas instâncias superiores que definem os caminhos da Educação. 
A revisão dos conceitos da legislação, elaborados de forma mais clara e de modo que valorize o status da Educação Física realmente como componente curricular e área de conhecimento, talvez possa ser o primeiro passo para sua re-significação no cenário educacional.

É inegável que a LDB 9394/96 trouxe mudanças para a área de Educação Física. Se por um lado a transformação de "atividade" para "componente curricular" trouxe ganhos ao status da área, além de desdobramentos positivos, como os diversos PCN's, um novo olhar dos acadêmicos, respaldo da garantia de aulas na Educação Básica, entre outros; por outro, desnudou-se o quanto a área necessita de dispositivos legais para reger necessidades que deveriam, há muito, terem sido conquistadas pelos profissionais da Educação Física brasileira.

\section{REFERÊNCIAS}

${ }^{1}$ BETTI, M. Educação Física e sociedade. São Paulo: Movimento, 1991.

${ }^{2}$ CASTELlani FILHO, L. Educação Física no Brasil: a história que não se conta. 9. ed. Campinas: Papirus, 2003.

${ }^{3}$ GAMBINI, W. J. J. Motivos da desistência em aulas de Educação Física no segundo grau. 1995. Trabalho de Conclusão de Curso (Graduação em Educação Física) - Instituto de Biociências, Universidade Estadual Paulista, Rio Claro, 1995.

${ }^{4}$ CAUduro, M. T. O desinteresse pela aula de Educação Física no Ensino Médio. Lecturas Educación Física y Deportes, Buenos Aires, ano 11, n. 106, 2007. Disponível em: www.efdeportes.com. Acesso em: 05 out. 2009.

${ }^{5}$ DARIDO, S. C. A Educação Física na escola e o processo de formação dos não praticantes de atividade física. Revista Brasileira de Educação Física e Esporte, São Paulo, v. 18, n. 1, p.61-80, 2004. 
${ }^{6}$ SOUZA JÚNIOR, O. M.; DARIDO, S. C. Dispensas das aulas de Educação Física: apontando caminhos para minimizar os efeitos da arcaica legislação. Pensar a Prática, Goiânia, v. 12, n. 2, p.1-12, maio/ago. 2009.

${ }^{7}$ CASTEllani FilHO, L. Política educacional e Educação Física. Campinas: Autores Associados, 1998.

${ }^{8}$ SOUSA, E. S.; VAGO, T. M. A nova LDB: repercussões no ensino da Educação Física. Presença Pedagógica, v. 3, n. 16, p.19-29, jul./ago. 1997.

${ }^{9}$ BRASIL. Ministério da Educação. Lei no 9.394/96, de 20 de dezembro de 1996. Estabelece as diretrizes e bases da educação nacional. Brasília, 1996.

${ }^{10}$ SILVA, E. V.; VENÂNCIO, L. Aspectos legais da Educação Física e integração à proposta pedagógica da escola. In: DARIDO, S. C.; RANGEL, I. C. A. (Coord.). Educação Física na escola: implicações para a prática pedagógica. Rio de Janeiro: Guanabara Koogan, 2005. p. 50-61.

${ }^{11}$ BRASIL. Ministério da Educação e Cultura. Secretaria de Educação Fundamental. Parâmetros Curriculares Nacionais: Educação Física. Brasília, 1998.

${ }^{12}$ SOUZA JÚNIOR, O. M.; DARIDO, S. C. As questões de Educação Física no Enem: um divisor de águas ou apenas mais um aspecto? Motriz, Rio Claro, v.17, n. 1, p. S1-S523, jan./mar. 2011.

${ }^{13}$ SOARES, C. L. et al. Metodologia do ensino da Educação Física. São Paulo: Cortez, 1992. 